\title{
XX Jornades d'Història de l'Educació. Cohesió Social i educació, Universitat de Girona, 2012, 565pp.
}

Les trenta-sis ponències que componen aquest volum aporten, en llurs diversos àmbits de treball, reflexions generals $\mathrm{i}$ treballs de camp que permeten de tornar a incidir sobre el concepte 'cohesió social' a través de les intervencions pedagògiques i educatives.

En principi, capitalisme (postfordista), cohesió i inclusió social són termes difícilment complementaris quant a relació. El Mode de Producció Capitalista, entès com a complex econòmic, ideològic i polític remet, com és sabut, a una manca de distribució "igualitària" de la plus-vàlua derivada del treball. En cas contrari, la reproducció social d'aquest sistema coercitiu no tindria condicions de possibilitat. A l'albada d'aquest nou segle, les condicions de treball, les discriminacions negatives pel que fa a l'accés a la nova força productiva emergent -la informació- i la construcció d'una nova aristocràcia, de nous oligopolis econòmics que determinen les orientacions de les necessitats "culturals" del mercat, incideixen de ple en la pràctiva educativa. El fet que es continuï considerant com a mercaderia és un repte que resta obert en aquesta època hegemonitzada per les anomenades 'tècniques de la informació i del comunicació'.

Però no partim de zero. Els treballs que apleguen aquest volum permeten d'escatir cruilles i horitzons que volen esquerdar el mur de la marginalitat social. Amb tot, cal demanar-se per l'abast de qüestionament de les bases polítiques i econòmiques que defineixen l'exclusió social el segle XXI. 'Exclusió social', doncs, com a neologisme de sobreexplotació de la força de treball i construcció de la nova pobresa (no exclusivament econòmica). Malgrat aquest darrera qüestió, que creiem fonamental, el conjunt de recerques tracten categories essencials: pensament pedagògic, identitat i treball social comunitari, formes de sociabilitat revolucionàries, llocs de memòria, iniciatives educatives formals d'orientació cooperativa-tercer sector-capital social.

El primer àmbit de treball -"propostes teoricopedagògiques i polítiques entorn de la cohesió social al llarg del segle XX"- aporta, en part, una visió retrospectiva, amb valor referencial de present, pel que fa a models educatius (Jaume Carbonell), ètiques i responsabilitats col-lectives delimitades pel biaix nacionalitari (Jordi Monés) i plantejaments intel-lectuals transformadors prenent com a exemple l'obra d'AlfonsCarles Comin (Joan Soler). En aquest sentit, també cal tenir en compte, com 
aprofundeix Xavier Tornafoch, les cosmovisions pedagògiques antagòniques republicanes i francofalangistes establertes en les polítiques editorials.

Cal però, no reduir mecànicament 'cohesió social' a sociologisme, o anàlisi de l'estructura social aïllada (políticament) del marc nacional de pertinença. En aquest sentit el treball d'Alà Baylac -"l'ensenyament de la llengua i la cultura catalanes com a eina de doble integració a Catalunya Nord"- incideix en el procés de (re)catalanització cultural -enfront de la francesització lingüística (i política)- com a estratègia de cohesió nacional-social. Aquest treball és, doncs, un bon model per a reflectir l'exclusió social sota formes d'estigmatització lingüística i d'identitat nacional (francès-glotofàgia versus català-llengua nacional).

Els dos àmbits següents -"Accions i experiències de cohesió social en l'àmbit educatiu reglat al llarg segle XX" i "Política, accions i experiències de cohesió social de l'escola en l'àmbit de la societat civil al llarg del segle XX"- tenen interès perquè aprofundeixen iniciatives que endeguen programes d'intervenció formativa en sectors socials minoritzats. Caldria, però, establir l'abast intermedi del concepte 'transformació social' en experiències determinades: les comunitats d'aprenentatge (Marc Sampé-Noemí Martín).

D'altra banda, cal també tenir en compte la manera com la sociabilitat ha impulsat formes d'articulació social amb un clar objectiu de socialització de la identitat cultural-nacional. El treball de Xisca Comas, Xavier Montillas, Bernat Sureda, Rosa Gené, Maria Llabrés i Immacula Picornell remarca llocs de memòria derivats de l'anàlisi gràfica de publicacions foranes de Mallorca, els quals reflecteixen imaginaris sociabilistes. Aquest treball constitueix un exemple reeixit que pot servir de model per a d'altres estudis furturs als Països Catalans.

El conjunt dels set treballs d'aquest apartat recull, doncs, notòries recerques -entre sociohistòriques i sociològiques- que permeten de plantejar qüestions d'actualitat: burocratització versus iniciatives associatives de base davant la construcció d'una identitat de comunitat en sectors urbans socialment concebuts apriorísticament com a 'perifèrics' (Flores Opimi), o bé la funció de susbtitució davant la fallida de l'estat del benestar (socialdemòcrata) pel que fa al combat contra l'exclusió social (Pere Fullana).

Els dos darrers apartats del volum -"L'educació a Andorra (segle XIX-XX) i "Aportacions a la historiografia educativa"- tenen un caràcter d'annex si remetem a l'objectiu de la Jornada. Amb tot, cal destacar com a objecte de debat el replantejament i revalorització del pensament pedagògic des d'un doble vessant: a) el relleu de les biografies com a treball de microhistòria i b), com a cruïlla de diverses transversalitats del coneixement: la centraliat de la història intel.lectual (Xavier LaudoConrad Vilanou). Amb tot, potser caldria demanar-se sobre el sentit del concepte 'postsocial' i la història conceptual. Si be el terme 'concepte' és un calidoscopi de subjectivitats, vivències, significats, no caldria plantejar com s'ha construït històricament una categoria? La història conceptual, a més de definir-la paradigmàticament, cal arranar-la en el marc de la història viscuda. Així, els quatre paràmetres (massa closos?) proposats pels autors -dialèctica, síntesi, vitalisme i 
cibernètica- no caldria concebre'ls, també, des de la sociologia del coneixement? És a dir, com a resultant de factors contextuals i teòrics? L'anàlisi d'Octavi Fullat, situat pels autors dins el model dialèctic a comportaria remetre-la a l'antinòmia represa per Herbert Macuse 'Eros-Thanatos'...

Perquè l'objectiu 'cohesió social' no esdevingui un apaivagador de consciències, un invent moralista, cal tenir en compte -un cop més- que l'educació, com a fet sociopolític, és delimitada bàsicament (malgrat l'autonomia metodològica interna) per la ideologia dominant. Vull dir que la voluntat d'estudi, ben reflectida en aquest recull d'anàlisis, no ha de romandre aïllada de les estratègies -i de la pràctica- de radicalitat política, que són les que acaben per definir les condicions de possibilitat. Altrament, l'externalitat de context ara dominant acabarà per condicionar negativament (anava a dir 'anul-lar') la capacitat explicativa del mètode...

Xavier Ferré Trill. Departament de Pedagogia. Universitat Rovira i Virgili. 